\title{
A Framework Proposal for Regional-Scale Flood-Risk Assessment of Cultural Heritage Sites and Application to the Castile and León Region (Central Spain)
}

\author{
Julio Garrote ${ }^{1, *} \mathbb{0}$, Andrés Díez-Herrero ${ }^{2}\left(\mathbb{D}\right.$, Cristina Escudero ${ }^{3}$ and Inés García ${ }^{3}$ \\ 1 Department of Geodynamics, Stratigraphy and Paleontology, Complutense University of Madrid, \\ 28040 Madrid, Spain \\ 2 Geological Hazards Division, Geological Survey of Spain (IGME), 28003 Madrid, Spain; andres.diez@igme.es \\ 3 Risk and Emergencies Management in Cultural Heritage, Castile and León Regional Government, \\ 47014 Valladolid, Spain; escremcr@jcyl.es (C.E.); garsanie@jcyl.es (I.G.) \\ * Correspondence: juliog@ucm.es; Tel.: +34-91-394-4850
}

Received: 26 December 2019; Accepted: 21 January 2020; Published: 23 January 2020

\begin{abstract}
Floods, at present, may constitute the natural phenomenon with the greatest impact on the deterioration of cultural heritage, which is the reason why the study of flood risk becomes essential in any attempt to manage cultural heritage (archaeological sites, historic buildings, artworks, etc.) This management of cultural heritage is complicated when it is distributed over a wide territory. This is precisely the situation in the region of Castile and León (Spain), in which 2155 cultural heritage elements are registered in the Catalog of Cultural Heritage Sites of Castile and León, and these are distributed along the $94,226 \mathrm{~km}^{2}$ of this region. Given this scenario, the present study proposes a methodological framework of flood risk analysis for these cultural heritage sites and elements. This assessment is based on two main processing tools to be developed in addition: on the one hand, the creation of a GIS database in which to establish the spatial relationship between the cultural heritage elements and the flow-prone areas for different flood return periods and, on the other hand, the creation of a risk matrix in which different variables are regarded as associated both to flood hazard (return period, flow depth, and river flooding typology) and to flood vulnerability (construction typology, and construction structural relationship with the hydraulic environment). The combination of both tools has allowed us to establish each cultural heritage flood risk level, making its categorization of risk possible. Of all the cultural heritage sites considered, 18 of them are categorized under an Extreme flood risk level; and another 24 show a High potential flood risk level. Therefore, these are about $25 \%$ to $30 \%$ of all cultural heritage sites in Castile and León. This flood risk categorization, with a scientific basis of the cultural heritage sites at risk, makes it possible to define territories of high flood risk clustering; where local scale analyses for mitigation measures against flood risk are necessary.
\end{abstract}

Keywords: flood risk; cultural heritage; meso-scale; flood hazard; flood vulnerability; Castile and León; Spain

\section{Introduction}

The analysis of river flood risk is a basic aspect in any attempt to integrate river management, and it is included in the European Flood Directive (60/2007/EC). Flood risk analysis has multiple approaches based upon the type of elements at risk. These elements could be classified as tangible and intangible (thus bringing the analysis into the areas of economic or social risk, respectively) or as direct 
or indirect. However, elements such as cultural heritage (archaeological sites, historical buildings, artworks, etc.) are often located somewhere between both categories. This means they can be assigned an economic value (market value), while at the same time they represent the record of the history of human civilization, whose value is intangible.

This previously mentioned duality, but also mainly the irreversibility, of flood damage on cultural heritage (which cannot be reproduced once it has been destroyed) makes the prediction and assessment of the flood risks that may affect these sites a critical task for their preservation. Given this situation, the first natural disaster management strategies that included cultural heritage among its objectives began to be developed in the 90s. Among these initiatives, one could highlight the "Carta del Rischio" [1], developed by the Italian Central Institute for Restoration since 1992, or the "Noah's Ark" [2] project of the European Union, launched in 2002.

There are many processes (natural or not) that can affect cultural heritage sites. Thus, references $[3,4]$ classify them into two major categories: unpredictable disasters and predictable deterioration. The former group would include Natural Disasters, and this subgroup, in turn, would include River Floods. These natural disasters, more frequent in recent years possibly due to global climate change, have a strong impact on cultural heritage $[5,6]$, much more than the predictable deterioration linked to cultural heritage elements of hundreds of year in age. For this reason, in 2009 the European Union financed the project "Cultural Heritage Protection against Flooding" with the aim of developing preventive strategies for the conservation of cultural heritage.

As these cultural heritage conservation projects began to develop, the first studies on the interaction between flood risk and cultural heritage began to appear. Lanza [7] was possibly the first to analyze this relationship in detail, focusing on the historical city of Genova. Subsequently, and also on a scale of analysis that considers the effects of river floods on historic cities with a high number of cultural heritage elements, mention should be made of the work in the city of Prague [8]; in the Thai city of Ayutthaya [9,10]; in the Iranian archaeological sites of Persepolis and Naghsh-e-Rostam [11]; in New Taipei, Taiwan [12]; in the city of Seville [13]; in the archaeological site of Mogao Grottoes, located southeast of the Chinese city of Dunhuang [14]; and in the city of Florence [15]. With a different approach, works such as [16] evaluate different physical processes associated with floods and the most common damages that these processes can cause on heritage elements (e.g., Díez-Herrero [17]). Meanwhile, Herle et al. [18] analyze the effect of floods on cultural heritage not from the point of view of the effect of surface water but from that of the structural problems associated with changes in the conditions of the terrain subsurface.

Most of the studies mentioned above focus on the damage to the cultural heritage associated with a single flood event (e.g., [8-11,13]), or the possible damage level to heritage due to floods with different return periods (e.g., $[12,14,15])$. Among the assessments that consider the "return period" variable in their analyses, most are based on the use of hydrological models for the simulation of the transformation process "precipitation-runoff" for the estimation of peak flows. While the analysis of Arrighi et al. [15] uses the coupled hydraulic 1D-2D model HEC-RAS to determine the flooded area, flow depths and flow velocities, [11,13] both try to analyze the effects associated with extreme events, with periods of flooding recurrence over 500 years.

The present assessment tries to overcome some of the limitations found in previous works, with the aim of defining the level of potential flood risk (even qualitatively) for the cultural heritage sites of a wide region, such as the Autonomous Community of Castile and León (Central Spain). To achieve this objective, the flood hazard associated with different return periods will be analyzed, as well as the flood vulnerability of the different types of cultural heritage catalogued within the studied region. Another type of vulnerability analysis, social and economic vulnerability against flash flood risk, has recently been done for this region $[19,20]$.

As mentioned above, some previous assessments of cultural heritage vulnerability have lags and uncertainties (subjectivity in used criteria, generalized BICs or "cultural heritage site" classifications, etc.), which do not render them invalid. Therefore, as improvements to the previously made 
assessments, the data considered for flood hazard assessment will be both hydrological-hydraulic as well as historical-documental and geomorphological (all of them linked to the information available in the Flood Prone Areas Cartography National System). From the point of view of flood hazard analysis, taking into account not only the return period of flooded areas but also the water depth and time lag, which improve the quantification of flood hazard. From the point of view of flood vulnerability analysis, taking into account the variety of cultural heritage elements catalogued, the approach has focused on the typology of the cultural heritage elements and its relationship with the hydraulic environment. Based on these variables, a matrix of potential flood risk has been developed for a flood risk categorization of cultural heritage sites. A GIS geodatabase helps us to integrate flood hazard and vulnerability values for each cultural heritage site. The quantification of the flood risk level in each cultural heritage site has allowed us to analyze the spatial distribution of this risk (clustering of flood risk results), as well as the ordered categorization of the patrimonial elements according to their risk level. All this will allow a scientifically based selection of single or geographically-linked groups of cultural heritage sites for the micro-scale assessment of their flood risk.

\section{Materials and Methods}

Castile and León is the most extensive region of Spain (and the third largest in Europe; more so than several European countries). It is located in the central-northern sector of the Iberian Peninsula and covers an area of $94,226 \mathrm{~km}^{2}$. From the hydrological point of view, the main basin is that of the Duero River and its tributaries; although it also participates in the basins of the Tajo, Miño-Sil, and Ebro rivers. The population of Castile and León is 2.41 million inhabitants (data at 1 January 2018; with a low population density of $25.67 \mathrm{pop} . / \mathrm{km}^{2}$ ), spread out over 2248 municipalities, mainly in the cities. Regarding the cultural heritage, this region has catalogued 2155 sites of cultural interest, some of them declared World Heritage by UNESCO (BICs affected by 500-year return period flood are showed in Figure 1); being the region of Spain with the most heritage assets and one of the largest in Europe and around the World.

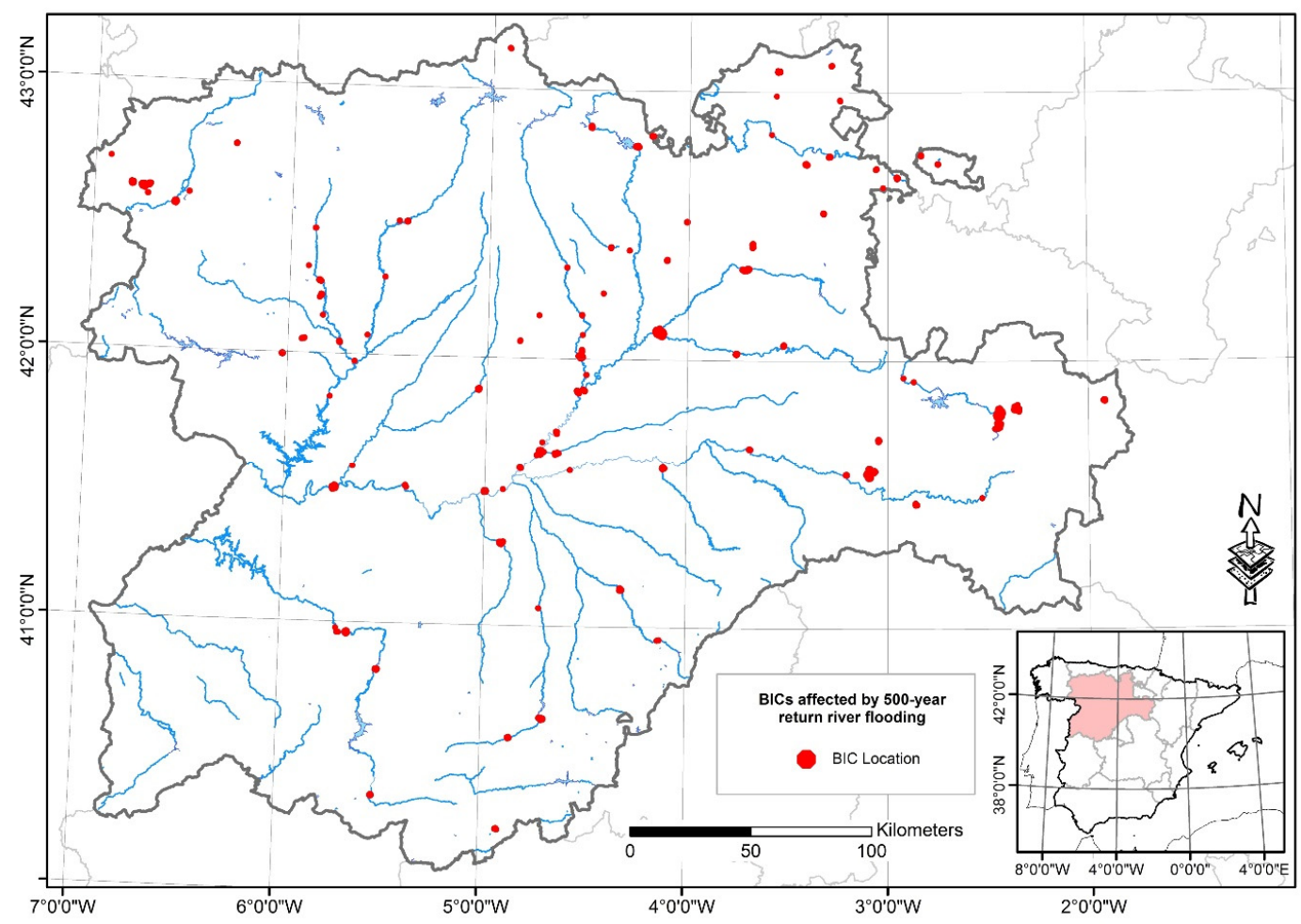

Figure 1. BICs location map for Castile and León region. 
Figure 2 shows a methodological flow chart developed for the estimation of flood risk in the cultural heritage elements or sites (hereinafter referred to as BICs) analyzed. It shows the previous studies (not included in this work) that serve as data sources for this study, the methodological stages, and the techniques used and the final results.

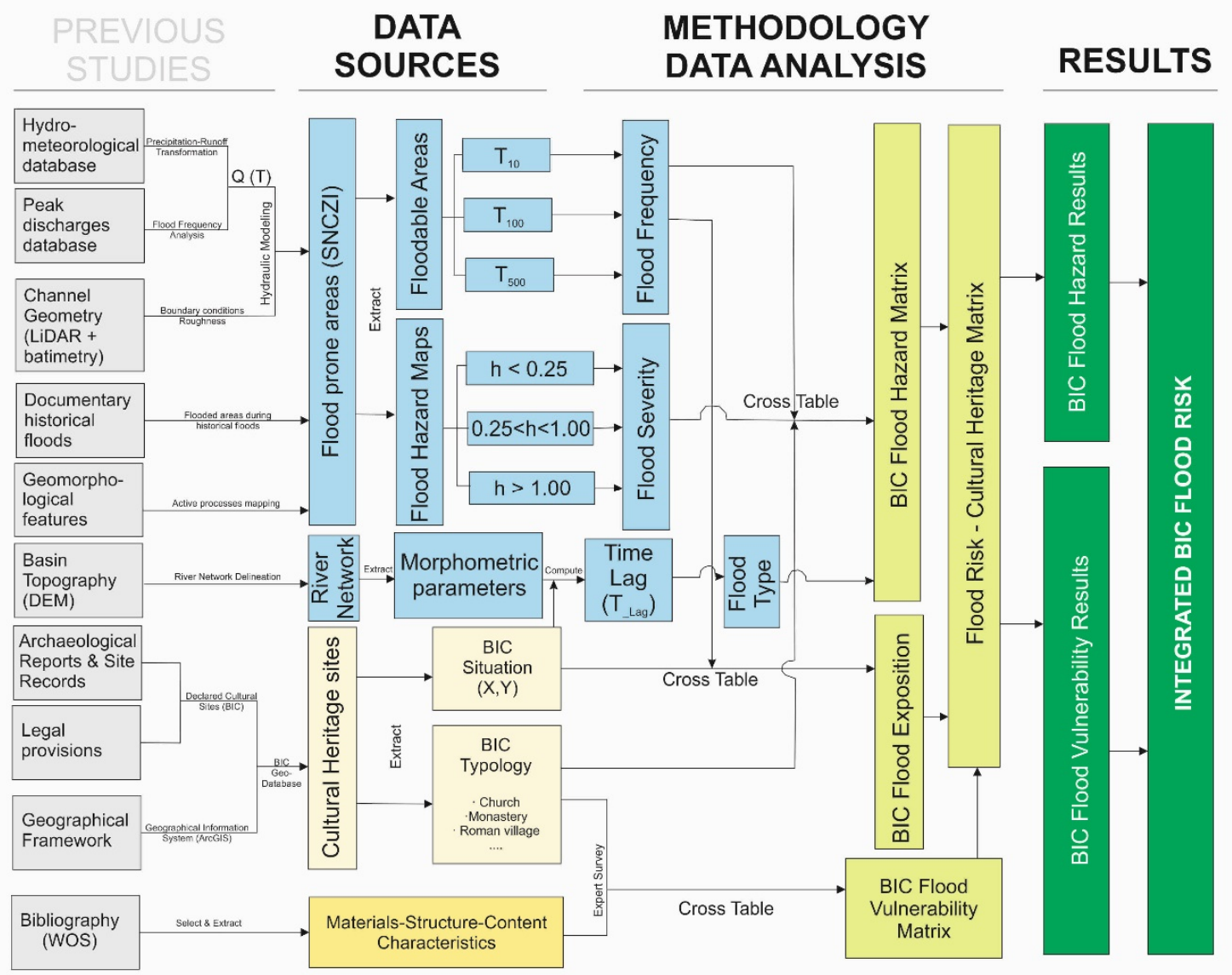

Figure 2. Methodological flow chart developed for the estimation of potential flood risk in the cultural heritage elements or sites. " $\mathrm{T}$ " is return period (in years), and " $\mathrm{h}$ " is water depth (in meters).

\subsection{Flood-Prone Area Delimitation and Associated Frequency}

In the present study, the delimitation of flood-prone areas for different return periods has been based on the information available in the Floodable Zones Mapping National System (hereinafter SNCZI; https://sig.mapama.gob.es/snczi/) for the territory of Castile and León. In this spatial database, four return periods of overflowing are included, associated to 10, 50, 100, and 500 years, so both ordinary floods (high frequency) and extraordinary floods (low frequency) are considered at an spatial resolution of $1 \times 1 \mathrm{~m}$.

For the delimitation of the floodable zones associated with the different return periods, three independent and complementary information sources have been used: hydrological-hydraulic data, documentary records of historical floods, and geomorphological information. The methodology used for the combination and integration of these data sources is described in [21,22].

In total, the number of floodable zones identified (areas with significant potential flood risk; hereinafter, ARPSIs) within the territory of Castile and León amounts to 405, with a total length of $3676 \mathrm{~km}$. This set of river reaches gives rise to a total floodable area, for the 500-year return period, of $1585 \mathrm{~km}^{2}$, only $1.7 \%$ of the extension of Castile and León. 


\subsection{Cultural Heritage Sites in Castile and León}

The identification of the patrimonial elements considered in this study comes from the BIC Catalog of Castile and León (https://servicios.jcyl.es/pweb/portada.do). They are collected in a georeferenced database in several polygon shapefiles, with associated attribute tables, in ArcGIS shapefile format (ESRI Geosystems). From the set of patrimonial elements, selection was made of those that were located spatially in the areas for which information was available regarding the floodable areas for different return periods. Thus, of the 2155 BICs (cataloged in February 2019) located in the territory of the Castile and León region, only 145 have been considered in this study for their interference with floodable areas described in the previous section.

All the BICs considered in the present work have legislative protection due to their importance and contribution to the cultural heritage of the Castile and León region. This means that the regional government must maintain and conserve the elements in the best possible conditions and limit the possible degradation or destruction processes that could affect them.

\subsection{Flood Risk-Cultural Heritage Matrix Development}

The development of risk matrices for heritage buildings is an analytical methodology that has already been used previously $[13,15,23]$. However, the complexity or degree of detail of the matrix developed in this work significantly exceeds that of previous proposals. In the case of the works of Ortiz et al. [13,23], the matrix developed did not assess only the effect of floods, but it was a multi-risk analysis, including rainfall events, temperature, and anthropogenic factors as fires, vandalism, or tourist pressure. Additionally, the effect of the floods was considered qualitatively [13] or simply based on the distance to the river channels [23]. In reference [15], the matrix only considered two variables, the return period (hazard factor) and the potential damages (vulnerability factor), and both qualitatively.

In the present work, the flood risk analysis of the Castile and León BICs (Figure 1) uses three complementary matrices: the analysis of flood hazard, the vulnerability analysis of BICs against floods, and the estimation of flood risk associated with the BICs (Figure 2).

The hazard matrix was developed using the information and characteristics of the floodable areas of the Castile and León region stored in the spatial database of the SNCZI. Three variables associated with the flood characteristics and their possible influence on the flood hazard in the BIC locations have been used: (1) places affected by floods with a return period of 10, 100, and 500 years; (2) water depth ("h" in Figure 2) for each of these three return periods; (3) flood type (flash-flood or gradual). The identification of the flood type, as USACE [24] considered, has been based on the variable T_lag (time lag, or the time between the center of mass of precipitation hyetograph to the center of mass of runoff on the hydrograph; used for the classification of floods as flash-floods $[25,26]$ ) as a measure of the available response time against floods. This variable takes into account the size of the watershed in the estimation of its value, with different formulations to estimate the $T$ _lag value depending on whether the river basin has an area lower or higher than $350 \mathrm{~km}^{2}$. Water depth is one of the most used variables in the analysis of the structural stability of buildings [27] and has a strong influence regarding this stability [28]. Water depths greater than $1 \mathrm{~m}$ (depending on their combination with other variables, such as flow velocity and building typology) greatly compromise the structural stability of buildings. In our hazard matrix, the flow depth boundaries have been developed from those used by USACE [24], adding a higher level on the scale. The combination of these three variables defines the six levels of flood hazard (Table 1). 
Table 1. Flood hazard matrix for cultural heritage sites.

\begin{tabular}{|c|c|c|c|c|}
\hline \multirow{4}{*}{$\begin{array}{l}\text { Return Period } \\
\text { (T, Years) }\end{array}$} & \multirow{4}{*}{$\begin{array}{l}\text { Depth } \\
\text { (m) }\end{array}$} & \multicolumn{2}{|c|}{ SEVERITY $^{1}$} & \\
\hline & & \multicolumn{3}{|c|}{ Flood Type/Characteristic Times (Hours)/Basin Area $\left(\mathrm{km}^{2}\right)$} \\
\hline & & \multicolumn{2}{|c|}{ Flash Flood } & \multirow[b]{2}{*}{$\begin{array}{c}\text { Normal Flood } \\
\text { T_lag }>6 \mathrm{~h} \\
\mathrm{~A}>350 \mathrm{~km}^{2}\end{array}$} \\
\hline & & $\begin{array}{c}\text { Small Basin } \\
T \_l a g<2 \mathrm{~h} \\
\mathrm{~A}<350 \mathrm{~km}^{2}\end{array}$ & $\begin{array}{c}\text { Large Basin } \\
T_{-} \text {lag }<6 \mathrm{~h} \\
A>350 \mathrm{~km}^{2}\end{array}$ & \\
\hline \multirow{4}{*}{$\mathrm{T} 10$} & $>3.6$ & 6 & 6 & 6 \\
\hline & $1.8-3.6$ & 6 & 5 & 5 \\
\hline & $0.9-1.8$ & 5 & 4 & 4 \\
\hline & $<0.9$ & 4 & 3 & 2 \\
\hline \multirow{4}{*}{ T 100} & $>3.6$ & 6 & 6 & 5 \\
\hline & $1.8-3.6$ & 5 & 5 & 4 \\
\hline & $0.9-1.8$ & 4 & 4 & 3 \\
\hline & $<0.9$ & 3 & 2 & 1 \\
\hline \multirow{4}{*}{ T 500} & $>3.6$ & 6 & 6 & 5 \\
\hline & $1.8-3.6$ & 5 & 4 & 4 \\
\hline & $0.9-1.8$ & 3 & 3 & 2 \\
\hline & $<0.9$ & 2 & 1 & 1 \\
\hline
\end{tabular}

${ }^{1}$ Flood hazard levels: 1, Low; 2, Medium-Low; 3, Medium; 4, Medium-High; 5, High; 6, Extreme. Background colors are related to different levels in all tables and figures.

For the vulnerability matrix, the Castile and León BICs have been classified into 6 main categories and 16 sub-categories (Table 2). All of them can be regarded as real estate and range from buildings of a civil nature to hydraulic infrastructures, as well as archaeological sites or defensive structures of cities and towns. The main criterion for grouping them into classes and sub-classes (unlike their classification in the BIC Catalog of Castile and León) has been their degree of general vulnerability to floods. This vulnerability has been considered dependent on the BIC building characteristics (mainly type of construction material and structure) and BIC contents (furniture, pictures, documents, etc.), and its more or less direct relationship with water conduction or defense against floods. BICs may be built using different materials and structures and contain multiple types of elements, so the BIC vulnerability level was defined as a weighted sum of the maximum vulnerability level in each category (construction material, construction structure, and content) by an expert criterion. As content is the most vulnerable element, it had the highest weight in opposition to construction material (lowest weight factor). 
Table 2. Flood vulnerability matrix for cultural heritage sites.

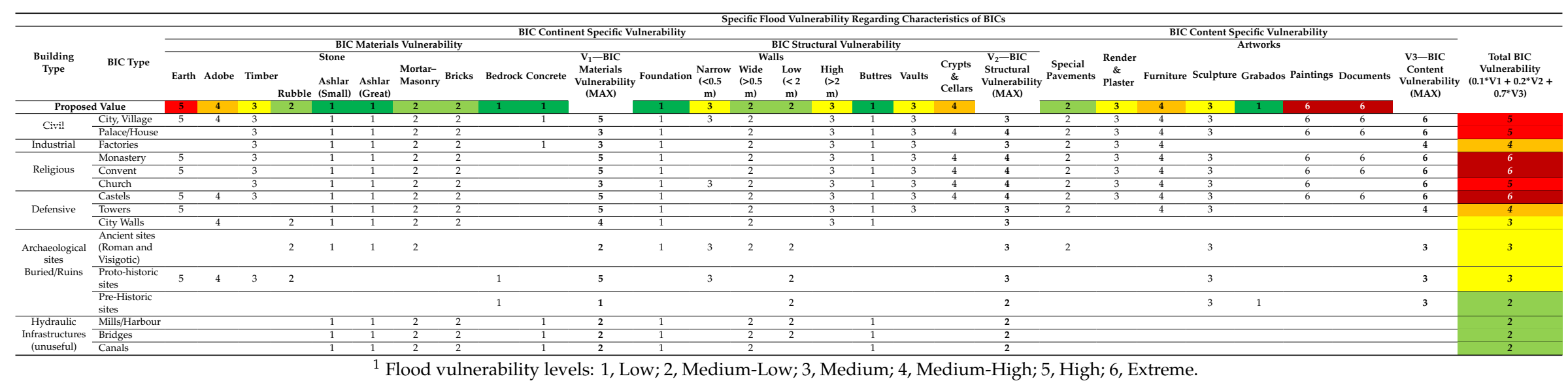


Finally, the potential risk matrix (Table 3) assumes a combination of the previous matrices, in which the combination of the six hazard levels and the six vulnerability levels generates the defined potential risk levels. The risk level has also been classified into six categories, from a low potential risk to an extreme potential risk. Not weighted factors have been used for the combination of hazard and vulnerability matrices, but the variable vulnerability was considered as more important in flood risk level final classification, again based on expert criterion and the cited technical literature. Finally, these matrices are implemented within a GIS, as conditional operations to obtain the values of hazard, vulnerability, and potential risk associated with the Castile and León BICs.

Table 3. Flood potential risk matrix for cultural heritage sites.

\begin{tabular}{cccccccc}
\hline \multirow{2}{*}{ Flood Risk $\boldsymbol{1}^{2}$} & \multicolumn{7}{c}{ Flood Vulnerability } \\
\cline { 2 - 9 } & 1 & 1 & 2 & 3 & 4 & 5 & 6 \\
\hline \multirow{3}{*}{$\begin{array}{c}\text { Flood } \\
\text { Hazard }\end{array}$} & 2 & 1 & 2 & 3 & 3 & 4 & 4 \\
\cline { 2 - 9 } & 3 & 2 & 2 & 3 & 3 & 4 & 5 \\
\cline { 2 - 9 } & 4 & 2 & 3 & 3 & 4 & 5 & 5 \\
\cline { 2 - 9 } & 5 & 3 & 3 & 4 & 4 & 5 & 6 \\
\cline { 2 - 9 } & 6 & 3 & 4 & 4 & 5 & 6 & 6 \\
\hline
\end{tabular}

${ }^{1}$ Flood risk levels: 1, Low; 2, Medium-Low; 3, Medium; 4, Medium-High; 5, High; 6, Extreme.

With respect to the interpretation of these flood risk levels, they can be interpreted as follows:

Risk levels 1 and 2 (Low and Medium-Low) correspond to cases where the level of risk can be accepted, and no important damages are expected for those cultural heritage sites.

Risk level 3 (Medium) corresponds to a case where the flood risk for the cultural heritage is at the limit of acceptability and should be monitored regularly. Low frequency or low vulnerability makes the flood risk acceptable.

Risk level 4 (Medium-High) is linked to a case where the level of risk is just not acceptable. The frequency or the vulnerability makes the flood risk not acceptable and a further analysis at micro-scale should be carried out with the objective to get a lower flood risk level.

Risk level 5 y 6 (High and Extreme) corresponds to a case where the level of risk is unacceptable and needs further micro-scale detailed assessments to define risk mitigation measures.

\section{Results of Flood Risk Assessment}

\subsection{Results of Flood Hazard Assessment}

From the point of view of the flood hazard analysis associated with the Castile and León BICs, as has been stated in the previous section, the data sources come from the flood depth maps derived from the detailed hydraulic models developed for the SNCZI. The intersection of this GIS layer with that which contains the spatial location of BICs gave us a result in which, for the return period of 10 years, the number of affected BICs amounts to 75; for the return period of 100 years, the number of affected BICs reaches 105; and finally, for the return period of 500 years, the number of BICs is 145 .

For the return period of 10 years, the flood depth for the $75 \mathrm{BICs}$ presents an average value of $1.38 \mathrm{~m}$ (with a standard deviation of $1.35 \mathrm{~m}$ ); and in a total of $40 \mathrm{BICs}$, the depth is greater than $1 \mathrm{~m}$. In the case of the return period of 100 years, the mean flood depth for the 105 BICs has an average value of $1.54 \mathrm{~m}$ (with a standard deviation value of $1.40 \mathrm{~m}$ ); there are $58 \mathrm{BICs}$ with a depth greater than $1 \mathrm{~m}$. Finally, in the case of the return period of 500 years, the mean flood depth for the total of $145 \mathrm{BIC}$ has a value of $1.71 \mathrm{~m}$ (with a standard deviation value of $1.68 \mathrm{~m}$ ), there being a total of 80 BICs in which the depth is greater than $1 \mathrm{~m}$. This set of values (Figure 3 ) indicates the high degree of variability in the flood depth values that affect the BICs in the study area. 


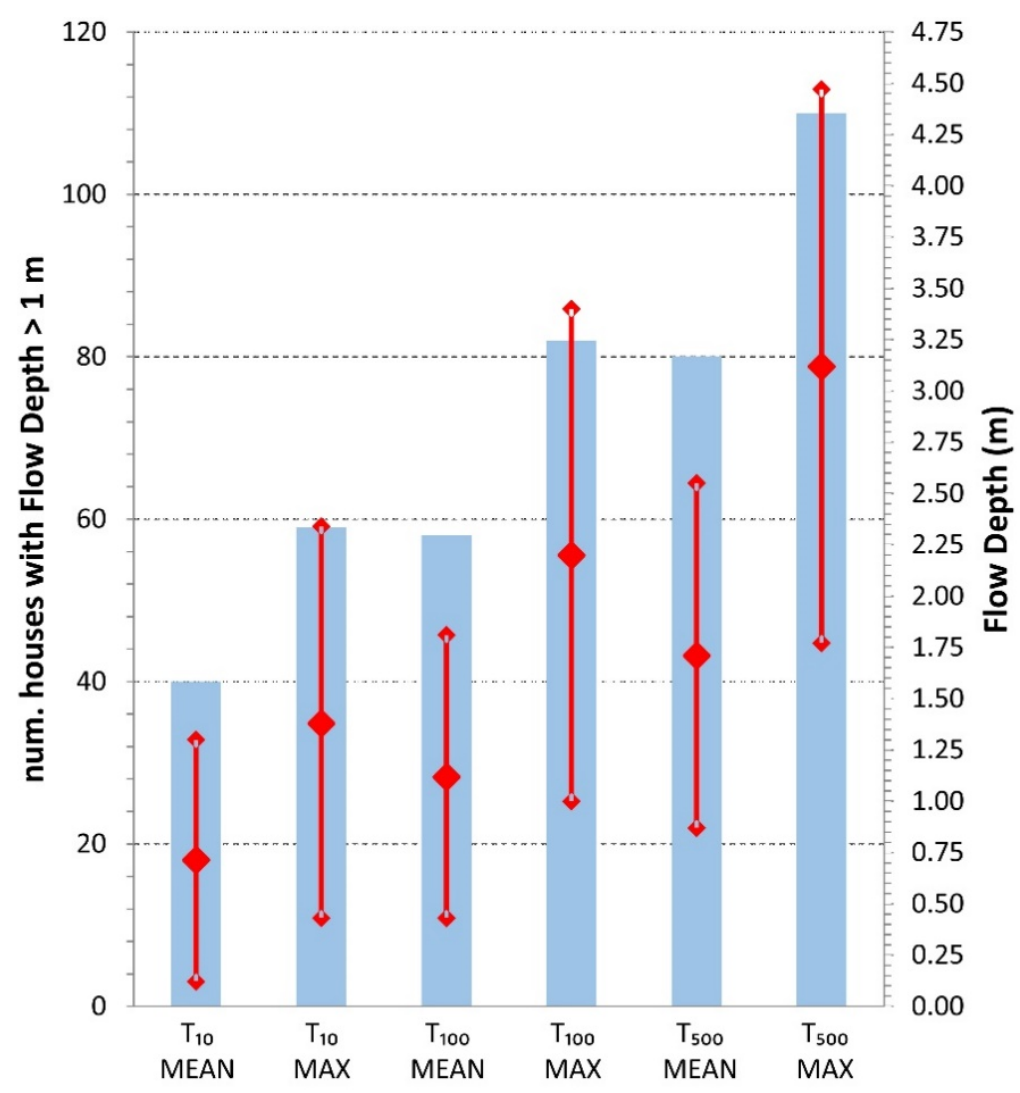

Figure 3. Flow depth values distribution (mean and 0.5 standard deviation, red line and dots) for the different return period considered. Blue bars show the number of BICs (considering average water depth and maximum water depth) where flow depth is up $1 \mathrm{~m}$.

Regarding the response time of the basin, measured from the variable "Time Lag (t_lag)", it is observed that in 37 BIC locations the value of "t_lag" is less than $2 \mathrm{~h}$; and in other 27 locations this variable is between 2 and $6 \mathrm{~h}$. These data indicate that in 64 of the $145 \mathrm{BICs}$ affected by floods, the response time to the flood is less than $6 \mathrm{~h}$.

Based on the results presented above, and through an iterative conditional process, the results of the flood hazard variable linked to the Castile and León BICs are shown in Figure 4. This graph shows the existence of 41 BICs with a High or Extreme hazard (33 and 8, respectively), and 73 BICs with a hazard above Medium. Meanwhile, the BICs that show Medium-Low and Low hazard values represent a total of 53 (24 and 29, respectively). The spatial distribution of the BICs and their flood hazard is reflected in the map in Figure 5, where the BICs with high hazard values are distributed around the peripheral municipalities and on the Pisuerga River axis; while the low hazard BICs are in the central part of the Castile and León region.

\subsection{Results of the Flood Vulnerability Assessment}

As previously stated, from the point of view of flood vulnerability analysis, the data sources come from the BIC Catalogue of the Castile and León region.

Thus, the set of 145 BICs viewed as susceptible to being affected by floods with a return period of 10,100 , or 500 years, were classified into 16 BIC types, grouped in 6 major categories. The distribution of flood vulnerability values based on the BIC building and content show that religious BICs are mainly the most vulnerable to floods. This is due to their buildings and, in particular, to the vulnerability of their contents. Aside from religious BICs, civil and industrial BICs (plus the castles, categorized into defensive BICs) show a high vulnerability to floods. On the other hand, archeological sites and mainly hydraulic structures show the lower vulnerability levels. It is important to keep in mind that just those 
types of BICs do not have contents, but only building (materials and structure). And the contents of the BICs just show the highest vulnerability values.

The spatial distribution of the BICs classified according to their vulnerability is shown in Figure 6.

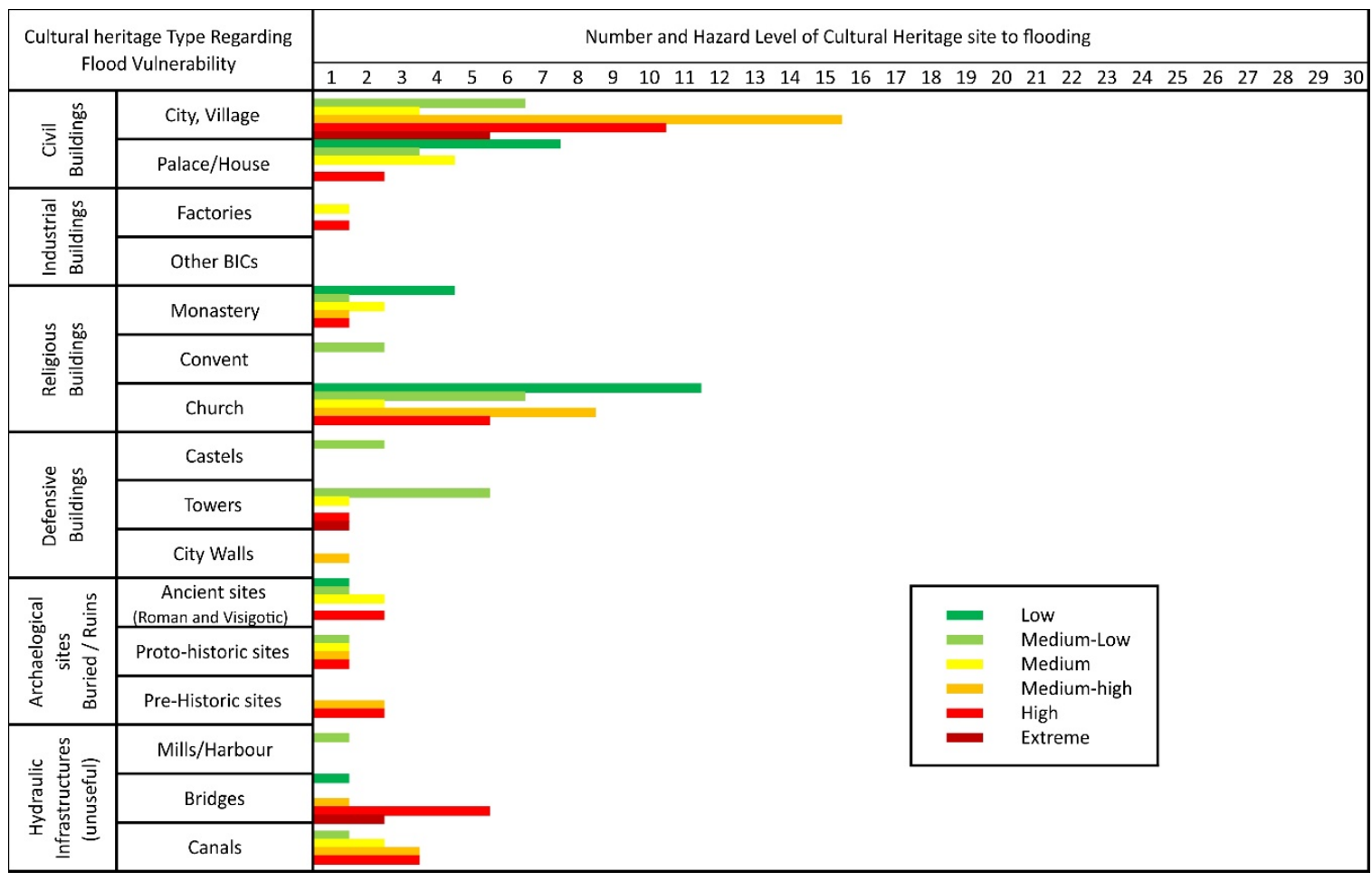

Figure 4. Distribution of flood hazard levels for the different cultural heritage types defined for Castile and León region.

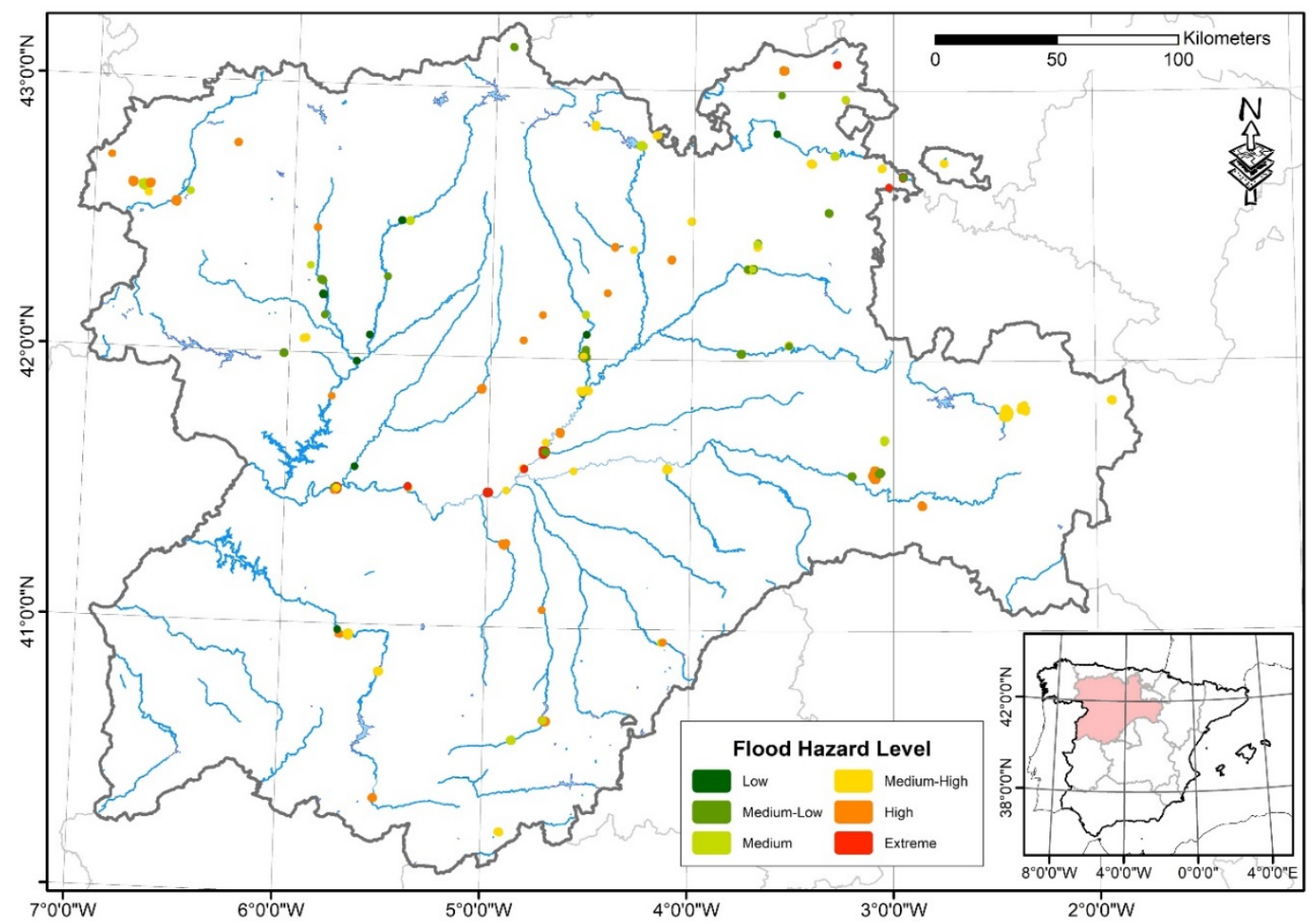

Figure 5. Spatial distribution of BICs in Castile and León region and their associated flood hazard level. 


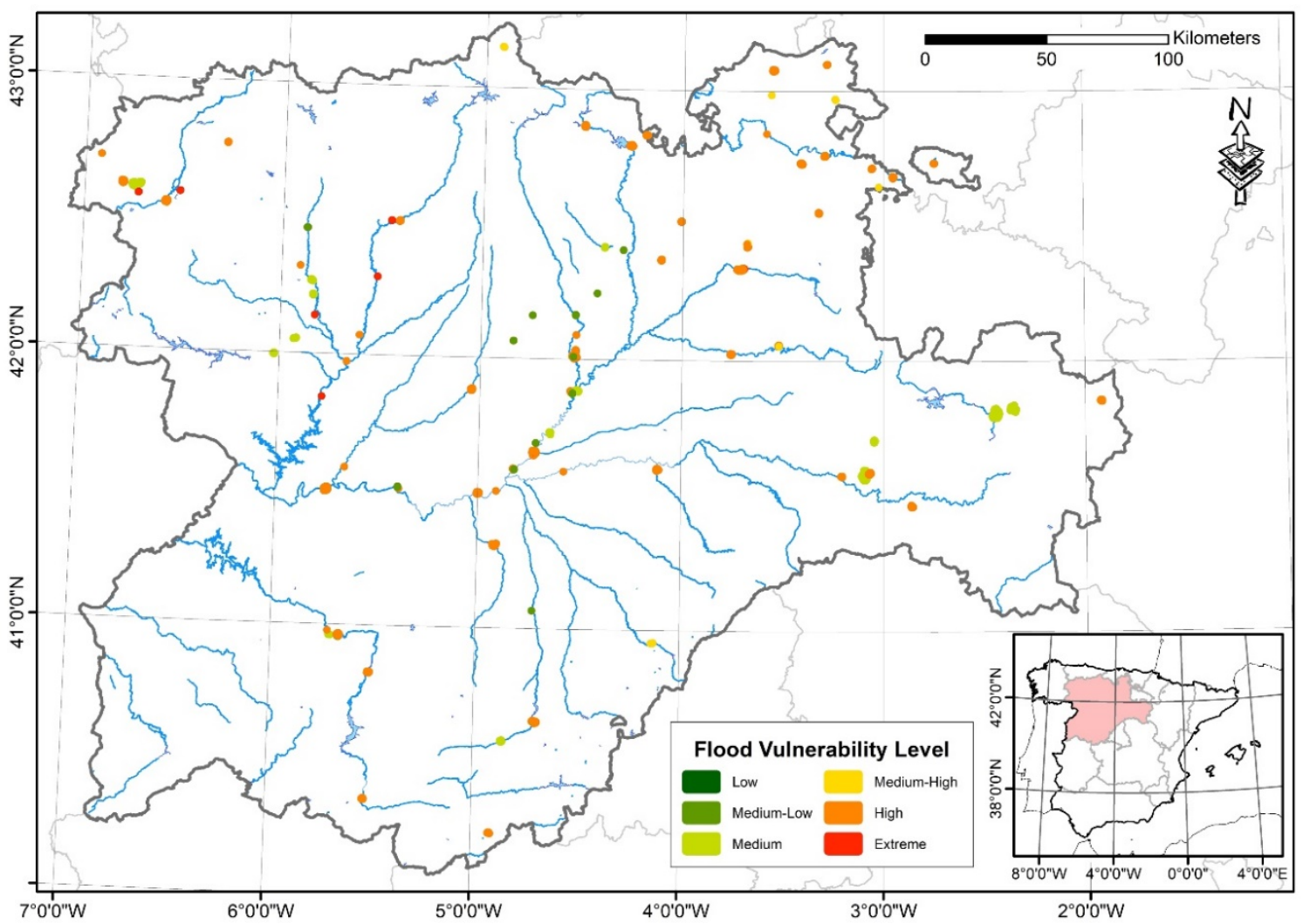

Figure 6. Spatial distribution of BICs in Castile and León region and their associated flood vulnerability level.

\subsection{Results of Flood Potential Risk Assessment}

Crossing the information related to flood hazards that may affect BICs with the BIC flood vulnerability has allowed us to define the level of flood potential risk with a return period of 10, 100, and 500 years for the Castile and León region.

The distribution of potential flood risk values based on the BIC typology is shown in Figure 7. This figure shows the existence of two types of BICs (historic cities and villages and monasteries) in which a level of Extreme potential risk is reached; rising to five types (the previous two plus palaces, churches, and towers) in those BICs that reach High or Extreme potential risk levels. In the opposite direction, eight types of BICs have levels of potential risk from Medium to Low (Medium, Medium-Low, and Low), which would be factories, towers, city walls, ancient sites, proto-historic sites, pre-historic sites, mills, bridges, and canals. Three of these eight typologies with medium or low levels are BICs that were originally associated with infrastructures related to water or rivers. This must condition their relatively low level of potential flood risk (associated with its low vulnerability).

From all the BICs considered, six of them present an Extreme level of potential flood risk; and another 44 show a High level of potential risk. This is around the $30 \%$ of the BICs considered as "affected by floods" in the present study. At the other extreme of the potential flood risk, 6 BICs present Low or Medium-Low risk levels (less than 5\%). The spatial distribution of these potential BIC risk values can be seen in Figure 8, where the BICs with high-risk values are distributed around the peripheral municipalities and in the central part of the Castile and León region. 


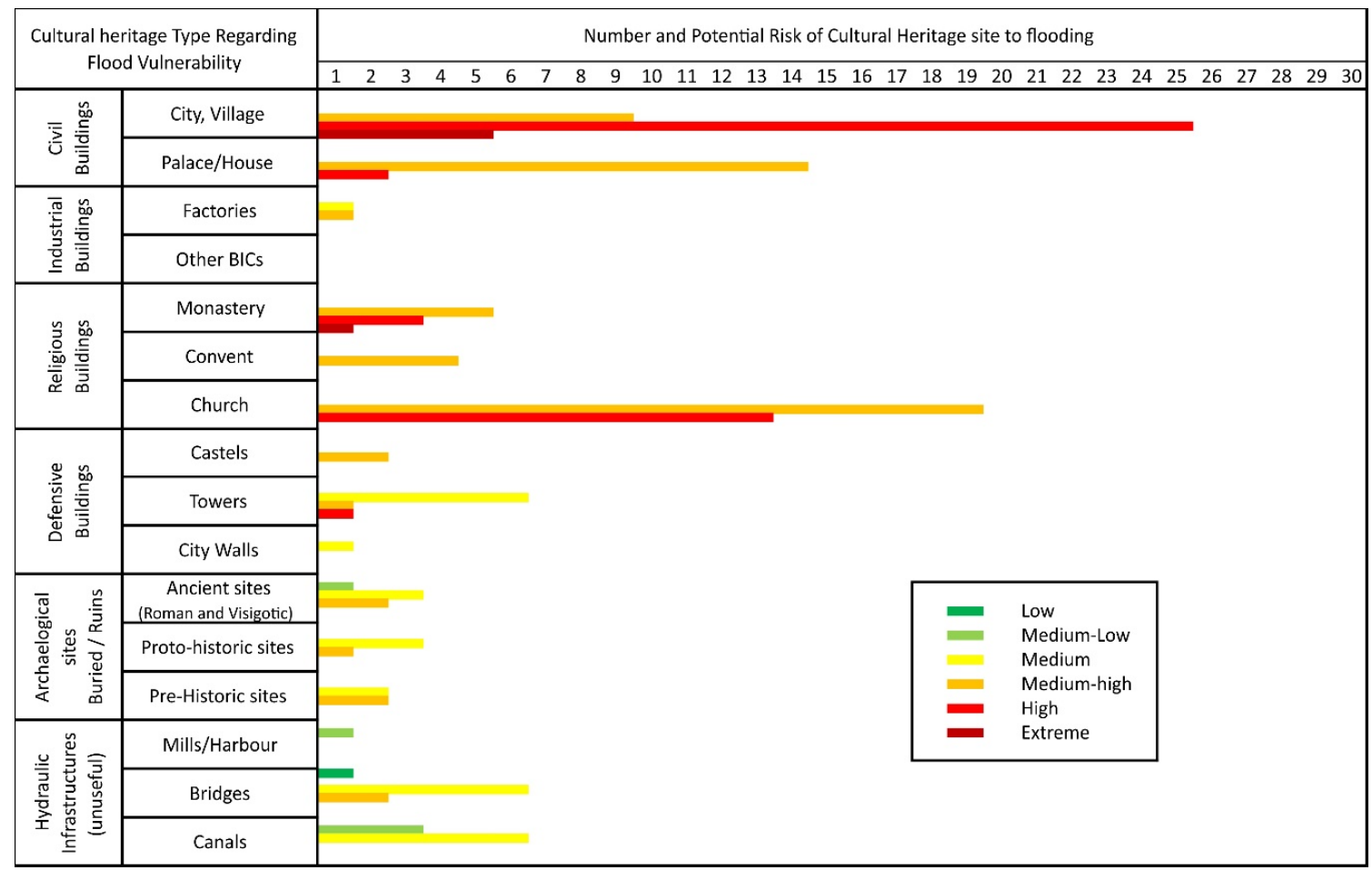

Figure 7. Distribution of flood potential risk levels for the different cultural heritage types defined for Castile and León region.

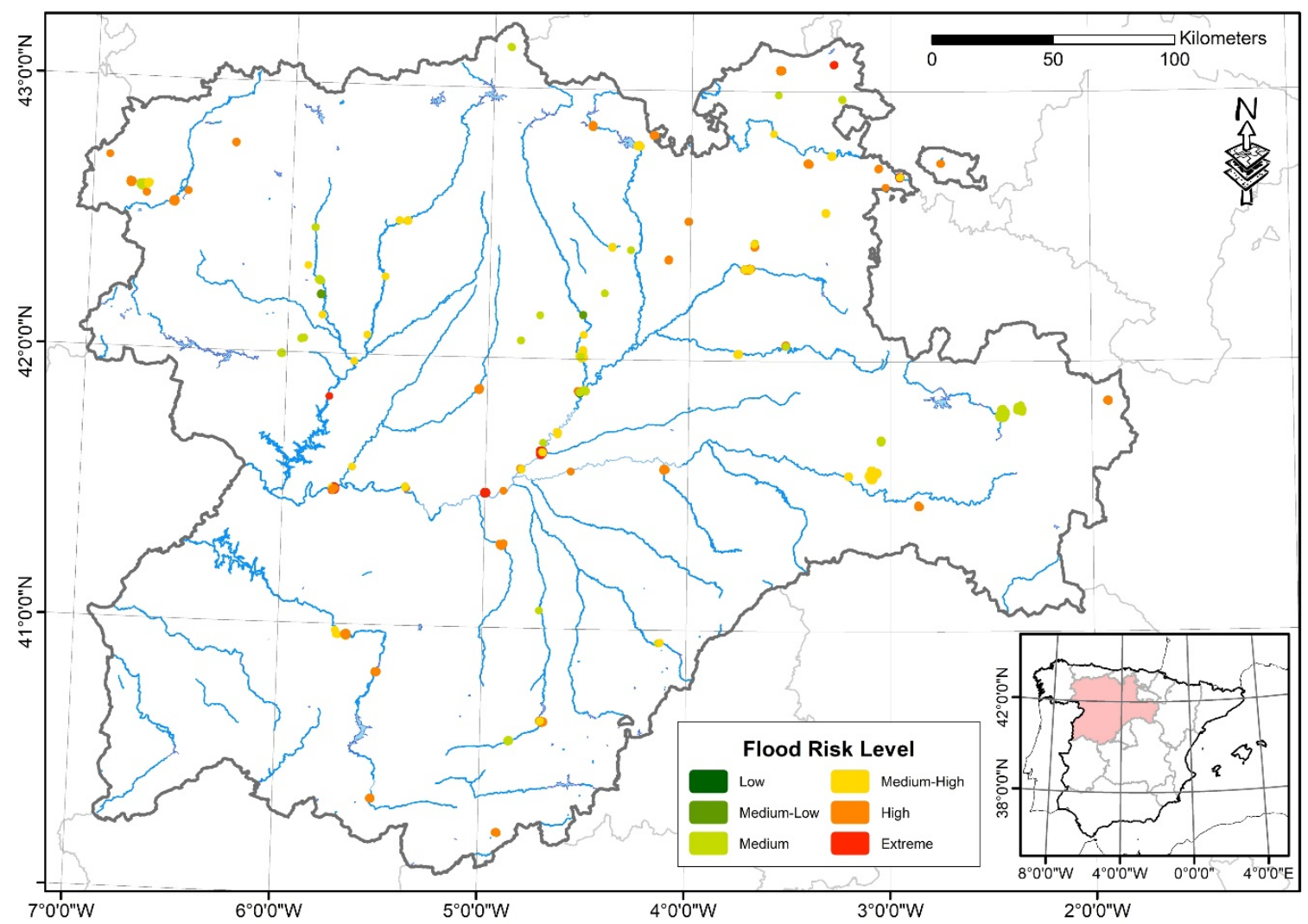

Figure 8. Spatial distribution of BICs in Castile and León region and their associated flood potential risk level. 


\section{Discussion}

To estimate the potential flood risk in the elements classified as Cultural Heritage sites in the Castile and León region, three matrices have been developed to encompass the analysis of flood hazard, flood vulnerability, and potential flood risk. When considering the proposed potential flood risk model, it must be considered that the approach of the present methodological framework has a regional and qualitative focus, albeit with quantitative classes for the matrix. This regional approach will therefore determine the variables to be used in each of the risk components, prioritizing the use of easy estimation variables, regional scope, and the possibility of being easily integrated into a GIS environment, which has been used as a key tool for the analysis.

Thus, from the point of view of the flood hazard analysis, the variables used were the flood return period, the flow depth, and the time lag of the drainage basin in which the flood occurs: all of them easily derivable variables from DTMs and hydrodynamic models. In this selection of variables, those that are more difficult to obtain on a regional scale have been left out, even if their use at a micro-scale or in analyses of individual buildings could be feasible (analyses of dynamic loads in structures, distribution of pressures, and structural deformations due to the fluid-structure interaction), as shown by [29].

Another aspect to be taken into account is the value associated with the flow depth variable and its relationship with the flood hazard analysis (10, 100, and 500 years return period) at the locations of cultural heritage sites. From the different approaches for the representation of buildings in hydrodynamic models (e.g., [30,31]), the one used in this work uses the elevation of the cells where the buildings are located. Thus, in order to obtain the flow depth value, one polygon feature that delimits the extension of the cultural heritage site (with a neighborhood buffer of $1 \mathrm{~m}$ around it) has been used.

In the present analysis, the flow depth used is defined as the mean value for each Cultural heritage site. However, this average value does not represent the maximum possible flow depth, and the difference between those values will depend on the topographic variability inherent in the terrain. Therefore, it would be appropriate to consider the optimum value of flow depth to be used for the flood hazard assessment. The minimum and maximum values would take us to the extremes of security, and therefore, when dealing with patrimonial elements of difficult recovery or reproduction, the option of the minimum value does not seem optimal or desirable. At the same time, the use of the maximum value would lead us to work within the worst possible scenario, a situation that could be considered viable or optimal depending on the importance of the elements at risk. However, the use of the maximum value can also lead us to consider extreme flood hazards supported by errors in the hydraulic model or, what may be more common, the terrain topography represented through an DTM. In this sense, as indicated by Vaze et al. [32], the use of LiDAR data has significantly improved the terrain representation in the DTMs. However, the urban areas (the majority in the location of cultural heritage sites) remain the most problematic and have the highest uncertainty, both in the correct representation of urban areas (e.g., References [33-35]) and in the results of the hydrodynamic models used to estimate flood hazard (e.g., References [31,36]).

Due to the above, the estimation of the flood hazard from flow depth values should use average or modal values, which indicate the most frequent or probable value within the cultural heritage site under consideration. Under this approach, it is possible that the most optimal option was the modal value. However, this option clashes with the type of flow depth data (real numbers with two or three decimal digits), which does not allow a correct estimation of the modal value because it would require categorization and provide less accurate results. Furthermore, when the water depth data available for a BIC are scarce (due to the fact that the BIC is not affected by flood in all its extension), the use of average water depth value may reduce the uncertainty about a possible error in water depth estimation. All in all, the option of the average value has been viewed as the optimum indicator for flow depths value related to each cultural heritage site. This average value should be considered representative of the flow depth in most cases, and only in situations of clearly bi-modal distributions 
with the maximums located at the extremes of the distribution, could we regard the mean value as a non-representative measure of this variable.

Even when regarding the average flow depth value as optimal, we proceeded to analyze the change in the results that would occur if the flood hazard estimate was based on the maximum flow depth values for each cultural heritage site. Figure 9 shows the variations in the distribution of flood hazard and potential flood risk values for cultural heritage sites based on the use of the mean or maximum flow depth values. In general, and as it would be logical to use the maximum flow depth value instead of the average value, the flood hazard in cultural heritage sites increases. For flood hazard data, a clear change in BIC hazard level distribution is observed where the number of BICs in levels 5-6 (High and Extreme) increase against the number of BICs in hazard levels 1-4. In the case of potential flood risk, the shape of the distribution of BICs into risk levels remains similar, with the curve distribution for maximum flow depth always under the curve distribution for average flow depth. This distribution shape drastically changes for the highest flood risk level, where the curve associated to maximum flow depth sharply increased. Therefore, using average or maximum flow depth does not draw a completely different results scenario, but a clear difference can be pointed out between them. Maximum flow depth data leads us to an increase of high flood risk, although the possibility that these results are due to errors in the data sources used is also higher than if we use average flow depths.

These tendencies are in line with what was pointed out by [31], although here it is observed that the influence on the flood hazard estimate does not undergo modifications as significant as those shown in that study, which focused on the assignment of the flow depth to each building. In addition, the results obtained in the present work would support: (1) the consistency of the use of average flow depth as a key factor for flood hazard assessment; and (2) the negligible influence of possible anomalous flow depth point values in the study area.

Regarding the analysis of the flood vulnerability for cultural heritage sites, a qualitative approach has been proposed that takes into consideration, on the one hand, the building materials and structural relationship with the hydraulic parameters, and on the other hand, the different continent elements of each BIC. This is an approach that is undoubtedly less detailed than others (e.g., References $[37,38]$ ) previously used for the study of the vulnerability of buildings to flooding, which focuses on the analysis of vulnerability at a building scale (through the use of magnitude-damage functions in which the magnitude is associated with the variable flow depth and flow velocity or through physical models that analyze the impacts and fluid-structure interactions). The previously cited vulnerability models focus mainly on residential buildings, without the particular characteristics of cultural heritage sites.

A variable that has sometimes been introduced in the analysis of flood hazard and flood vulnerability is the flow velocity. In this study, it has not been considered relevant for two reasons: (1) in a regional study and using such generic categories of cultural heritage types, it is very difficult to estimate the incidence of the average speed on their structural stability; (2) almost all the analyzed cultural heritage sites are in the flood-prone area, although they can be affected by high flow depths, but not by flow velocity; since they are usually located outside the path of the floodway, especially the oldest ones.

In those previous assessments in which the flood risk analysis took into account elements of cultural heritage (e.g., $[13,15])$, the variables used are similar to those used in the present study (flood return period, potential vulnerability depending on the type of cultural heritage). However, and because the present study focuses specifically on the risk of heritage elements, the flood hazard and flood vulnerability matrices generated are more complete and complex, since they include other variables such as flow depth, flood time lag (time lag), or a more detailed classification of the cultural heritage elements and its relationship with the hydraulic environment. This means that the results obtained can be considered to be more detailed, even if the work scale is similar to the previous proposals (city or regional scale). 

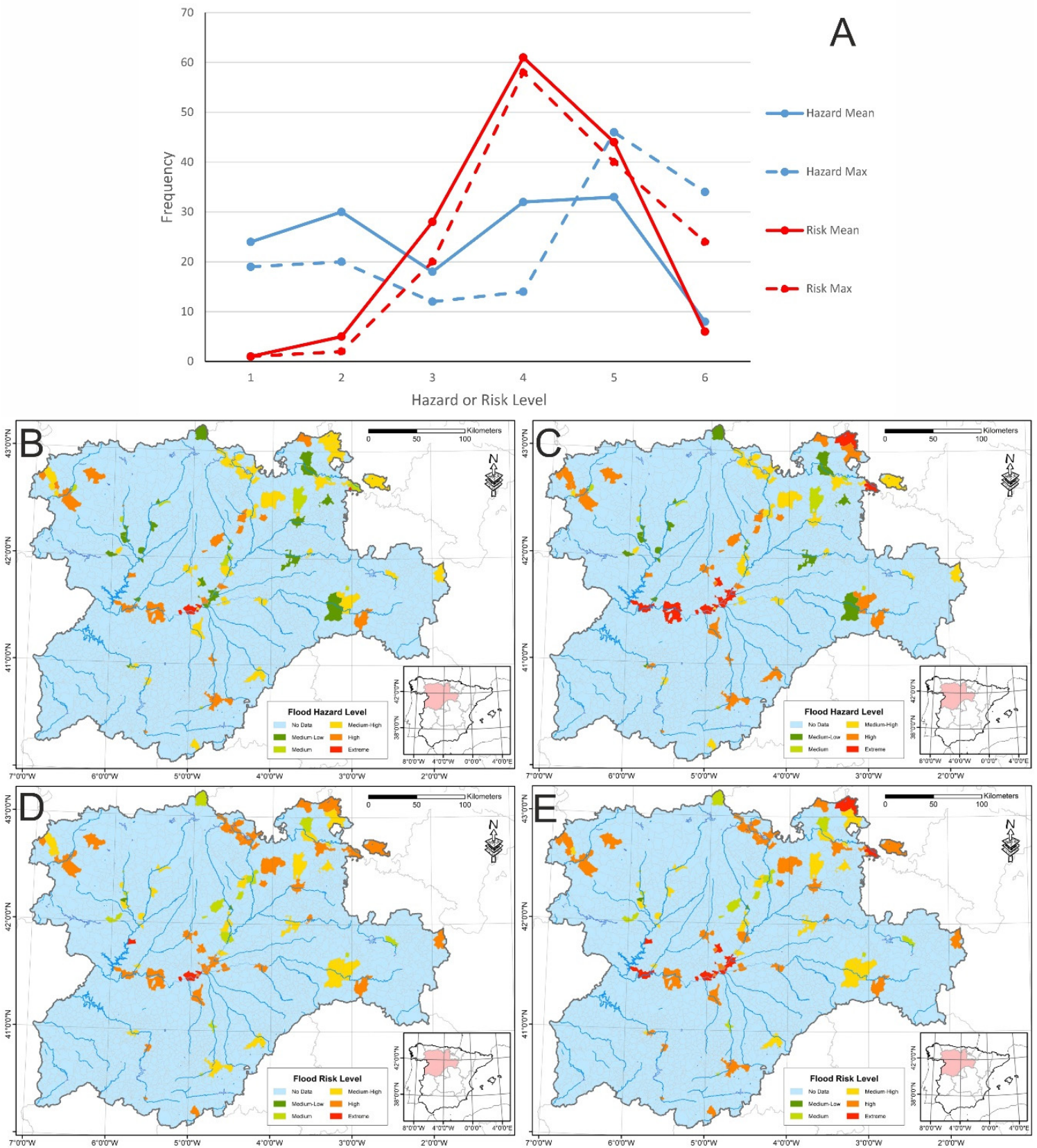

Figure 9. BICs frequency variations (A) for flood hazard and flood potential risk upon the use of mean or maximum flood depth values. Flood hazard spatial distribution at municipality level using average (B) and maximum (C) flow depth data. Potential flood risk spatial distribution at municipality level using average (D) and maximum (E) flow depth data.

An up-scaling process has been made, using the boundaries of the municipalities as the unit for display (Figure 9B-E). For both, flood hazard and potential risk, and increase in High and Extreme values is observed. Those changes are mainly concentrated along the Duero basin main river, and they are much less evident in the rest of the basin. Average and maximum flood hazard for each municipality (Figure 9B,C) do not show great differences, but the same patterns linked to the use of maximum values previously noted. Same situation is observed for flood risk (Figure 9D,E). Anyway, due to the variability of BICs types and vulnerabilities in a municipality, up-scaling process does not allow great advantages in analysis results beyond a simplification in its mapping.

For the working scale used here, it is possible, however, to include other variables, mainly related to the vulnerability component that would improve the estimation of the potential flood 
risk. These would be variables such as: (1) the structural conservation state of the cultural heritage, (2) the behavior of the construction material in contact with flood water, (3) the presence of mitigation measures against floods, etc. In relation to the experience in the region of Castile and León, however, this type of data is not included systematically in the databases of the Catalogs of Cultural Heritage Sites. To do so would require costly field and laboratory work that is not viable for analyses at the regional scale. Those data, however, are considered essential for local or micro-scale analysis.

At the assessment working scale, the limitations of the analysis come from data availability. Both hydrodynamic data (water depth, flow velocity, spatial resolution data, etc.) and vulnerability data (stored data about cultural heritage sites such as materials, structure, content, conservation, etc.) All those limitations are very similar to those pointed out by previous approach [39]. About hydrodynamic data, the scarce availability of data limits the possibility of regional analysis, and the data from European or Global projects have a spatial resolution not useful for cultural heritage sites flood risk analysis. From the point of view of vulnerability data, the limited number of tabulated variables (with much more information as plain text) makes difficult [39] a more complex and complete assessment of cultural heritage sites vulnerability to flooding.

We must keep in mind that the proposed methodological framework is a subjective proposal, based on the knowledge and authors' experience in both flood hazard and cultural heritage vulnerability. In this sense, the subjectivity of the proposal follows the line of previous proposals [40], in which the vulnerability of the cultural heritage and the flood hazard are also defined based on the authors' criteria.

The combination of the flood hazard and vulnerability matrices has made it possible to generate a matrix of potential flood risk that is easily implemented in a GIS environment and allows a quick visual analysis of the spatial distribution of the different levels of flood risk for cultural heritage elements and the identification of possible high flood risk "clusters" within them. However, a real clustering analysis may not be available due to the irregular spatial distribution of BICs and its dependence of the existence of associated flooding data. This visual analysis is also a perfect starting point for those flood risk and cultural heritage managers responsible for managing and safeguarding this irreplaceable heritage. These results can help to prioritize micro-scale flood risk analyses or directly implement flood mitigation measures in those places of greatest interest. For preventive conservation assessments at a regional scale, rather than use a high or extreme flood risk for an individual heritage site, it is convenient to look at high-risk clustering, which justifies a more detailed analysis at the local scale.

Finally, the methodological framework present here has the characteristic of being easy to replicate in other territories and settings. Flood hazard analysis may be replicated anywhere, and flood vulnerability too. About vulnerability, the matrix presented here may be used directly or may be adapted to the local characteristics of the cultural heritage sites where it will be applied. The vulnerability of each different building material, structure, or building content should be kept unchanged, but the vulnerability linked to each cultural heritage class could be different if the building material and structure or building contents have changed.

\section{Calibration and Validation of the Methodological Proposal and the Obtained Results}

The calibration and validation of the methodological proposal of this work, through its results, is very complex because it involves validating potential risk situations and not tangible and measurable scenarios, whose maps could be calibrated with the usual techniques for quality control in thematic cartographies. Therefore, in the international scientific literature, the calibration and validation of potential risk is usually addressed indirectly, through secondary risk variables and indicators [41,42]. However, in this case, the systematic quantitative validation of the results correlating them with indirect sources of past damage is also not feasible. This is due to the lack of correlation between the assigned risk and the volume and quality of documentary sources; having this lack of correlation a double cause: the scarcity and spatio-temporal bias of documentary information and the different spatial resolutions of the results and contrast information. 
Regarding the scarcity of information, not even the Spanish National Catalog of Historical Floods collects a significant number of past events (only 308 historical records, between 181 BC and 2010, throughout the whole Duero basin), which allow representative statistical analysis at BIC scale. The spatial bias is manifested in the fact that BICs that are located in municipalities with smaller populations and in rural areas (villages), have less historical documentary information, transmitting a false sense of lower potential risk; while the opposite occurs in the large populations of historical importance (towns and cities), which were important political, religious, or military populations in the past and, therefore, with a great capacity for documentary production. The temporal bias is manifested in the greater information on recent floods (19th and 20th centuries) compared to the old ones (prior to 18th century), due to the increased recent documentary availability (historical press since the mid-19th century) and regarding the perception of risk by populations over time.

The hazard and risk results of this study (analyzed at the BIC scale) have different spatial resolution regarding the available documentary sources, ranging from the BIC (damage technical reports and repair works), to the location (village, town, or city), to the municipality or region affected by past events. Therefore, there is no certainty that past documented events will affect the BIC or only its environment ("location" and "municipality" spatial resolution documentary sources). This uncertainty affects calibration and validation analysis.

As an alternative to systematic validation using all documentary production in bulk, the only feasible strategy is the in-depth study of specific examples representing high and low risk situations among the results of this work.

To begin with the BIC with high values of flood hazard and risk, the Royal Old Mint of Segovia is an architectural complex that has an extensive documentary record on historical floods and their consequences, from descriptions of damages to machinery and facilities for more than 30 historical floods, collected in the manuscripts of archives and libraries (General Archive of Simancas), to technical reports of detailed analysis of flooding (historical floods, $[43,44]$ ) and possible mitigation solutions. There is also a good qualitative correlation between another of the higher risk BICs, as "certain areas of the city of Medina de Rioseco" and the existence of technical reports on damage conditions by floods. Another positive example is the San Francisco convent in the city of Medina de Rioseco (medium risk) and how the mitigation actions carried out have reduced the flooding of this BIC [45].

In the opposite situation, that is, BIC with lower flood hazard and risk and few conditions and past damages, it is complex to find reliable examples, due to the mentioned space-time bias of the documentation. In that way, there are some BICs, such as the Roman villages of Camarzana de Tera (Orpheus) or Quintana del Marco (Los Villares), which are located in the flood zone for T500 years, and apparently have not suffered significant flood damage in the last 1600-1700 years since their construction (as evidenced by the conservation of very vulnerable elements, such as mosaics), so their flood risk must have been low or very low, as they have been assigned in the results of this study.

In summary, it can be considered that the methodology used and the results obtained have an acceptable agreement with the historical and actual flood risk of Castile and León BICs, not so much for a complete systematic validation but for the timely analysis of the results for representative singular BICs, which makes them useful as a qualitative approach to risk.

\section{Conclusions}

An easy-to-implement and low-cost methodology is presented here to determine the potential flood risk of cultural heritage sites at a regional scale. The methodological framework improves previously proposed approaches to cultural heritage flood risk assessment.

The methodological framework (with a focus on analysis at a regional scale) has been implemented in the region of Castile and León (Spain), which has a Catalog of Cultural Heritage Sites composed of more than two thousand elements that have different degrees of administrative protection. Although the model calibration and validation are not fully available due to the scarce data on historic flood events 
and damages, cultural heritage sites with different potential flood risk have been used to check the reliability of the model results, having obtained a good agreement between them.

The implementation of the three proposed matrices (flood hazard, flood vulnerability, and potential flood risk) in a GIS environment allows the estimation of the flood risk level presented by the cultural heritage elements and its classification.

The matrices implemented in the present assessment are based on a series of variables related to flood risk that are generally available or can be easily derived from DTMs. These characteristics make the study and proposed methodological framework easy to replicate.

The qualitative characterization of the potential flood risk for the heritage site and its spatial distribution, both direct results of the methodological framework proposed here, can and should serve as a key tool for cultural heritage managers at a city, region, or state administrative level. This should be presented in a way that facilitates the tasks of prioritization and allocation of economic items for the protection of cultural heritage, through preventive conservation.

Finally, the results obtained through the methodological framework proposed can and must also make it easier to prioritize flood risk analysis on heritage elements at a local or micro-scale level. The micro-scale analysis, due to its inherent level of detail, may use specific or ultra-detailed magnitude damage functions (in which the magnitude is defined from the combination of flow depths-flow velocities-flooding times-flood sediment) or physical models that analyze the interactions between fluid and structure (distribution of pressures, deformations, thresholds of collapse of structures, etc.).

Author Contributions: All authors made a significant contribution to the final version of the paper. Conceptualization, J.G. and A.D.-H.; flood risk analysis, J.G. and A.D.-H.; BICs data, C.E. and I.G.; writing-original draft, J.G. and A.D.-H.; writing-review and editing, all authors. All authors have read and agreed to the published version of the manuscript.

Funding: This research was funded by the project DRAINAGE, CGL2017-83546-C3-R (MINEICO/AEI/FEDER, UE), and it is specifically part of the assessments carried out under the coverage of the sub-project DRAINAGE-3-R (CGL2017-83546-C3-3-R).

Acknowledgments: The authors would like to thank to the Planning, Research and Dissemination Service of the General Directorate of Cultural Heritage of the Castile and León regional government for granting access to BICs data; and finally, Juan Francisco Arazola (Directorate General of Water of the Spanish Ministry of the Environment and Rural and Marine Affairs) for granting access to flood depth data of SNCZI.

Conflicts of Interest: The authors declare no conflict of interest.

\section{References}

1. Carta del Rischio. Available online: www.cartadelrischio.it/index.asp (accessed on 12 November 2019).

2. NOAH's Ark Project. Available online: https://cordis.europa.eu/publication/rcn/11779_en.html (accessed on 12 November 2019).

3. Ghose, S. Protection against natural and man-made disasters. In Risk Preparedness for Cultural Properties: Development of Guidelines for Emergency Response; Saito, H., Ed.; Chuo-Koron Bijustu Shuppan Co., Ltd.: Tokyo, Japan, 1999; p. 159.

4. Jung, F.C. From "Blue Shield" to disaster management: The awareness and actions of risk preparedness from world's cultural property. J. Cult. Property Conserv. 2010, 12, 43-56.

5. Štulc, J. The 2002 Floods in the Czech Republic and their impact on built heritage. In Heritage at Risk. Cultural Heritage and Natural Disasters; Meier, H.-R., Petzet, M., Will, T., Eds.; ICOMOS TUDPress: Dresden, Germany, 2007; pp. 133-137.

6. Will, T. Integrating technical flood protection and heritage conservation planning for Grimma, Saxony. In Heritage at Risk. Cultural Heritage and Natural Disasters; Meier, H.-R., Petzet, M., Will, T., Eds.; ICOMOS TUDPress: Dresden, Germany, 2007; pp. 139-152.

7. Lanza, S.G. Flood hazard threat on cultural heritage in the town of Genoa (Italy). J. Cult. Herit. 2003, 4, 159-167. [CrossRef]

8. Holicky, M.; Sykora, M. Assessment of flooding risk to cultural heritage in historic sites. J. Perform. Constr. Facil. 2010, 24, 432-438. [CrossRef] 
9. Daungthima, W.; Kazunori, H. Assessing the flood impacts and the cultural properties vulnerabilities in Ayutthaya, Thailand. Procedia Environ. Sci. 2013, 17, 739-748. [CrossRef]

10. Vojinovic, Z.; Hammond, M.; Golub, D.; Hirunsalee, S.; Weesakul, S.; Meesuk, V.; Medina, N.; Sanchez, A.; Kumara, S.; Abbott, M. Holistic approach to flood risk assessment in areas with cultural heritage: A practical application in Ayutthaya, Thailand. Nat. Hazards 2015, 81, 1-28. [CrossRef]

11. Naderi, M.; Raeisi, E.; Talebian, M.H. Effect of Extreme Floods on the Archaeological Sites of Persepolis and Naghsh-e-Rostam, Iran. J. Perform. Constr. Fac. 2014, 28, 502-510. [CrossRef]

12. Wang, J.J. Flood risk maps to cultural heritage: Measures and process. J. Cult. Herit. 2015, 16, $210-220$. [CrossRef]

13. Ortiz, R.; Ortiz, P.; Martín, J.M.; Vázquez, M.A. A new approach to the assessment of flooding and dampness hazards in cultural heritage, applied to the historic centre of Seville (Spain). Sci. Total Environ. 2016, 551-552, 546-555. [CrossRef]

14. Li, H.; Zhang, J.; Sun, J.; Wang, J. A visual analytics approach for flood risk analysis and decision-making in cultural heritage. J. Vis. Lang. Comput. 2017, 41, 89-99. [CrossRef]

15. Arrighi, C.; Brugioni, M.; Castelli, F.; Franceschini, S.; Mazzanti, B. Flood risk assessment in art cities: The exemplary case of Florence (Italy). J. Flood Risk Manag. 2018, 11, S616-S631. [CrossRef]

16. Drdácký, M.F. Flood Damage to Historic Buildings and Structures. J. Perform. Constr. Fac. 2010, 24, 439-445. [CrossRef]

17. Díez-Herrero, A. Patrimonio e inundaciones: ¿una relación de riesgo? In Actas del Congreso Internacional "Patrimonio Cultural y Catástrofes: Lorca como referencia", Lorca, Spain, October 3 2018; Asociación Hispania Nostra: Lorca, Spain, 2018.

18. Herle, I.; Herbstová, V.; Kupka, M.; Kolymbas, D. Geotechnical Problems of Cultural Heritage due to Floods. J. Perform. Constr. Fac. 2010, 24, 446-451. [CrossRef]

19. Aroca-Jiménez, E.; Bodoque, J.M.; Antonio García, J.; Díez-Herrero, A. Construction of an integrated social vulnerability index in urban areas prone to flash flooding. Nat. Hazards Earth Syst. Sci. 2017, 17, 1541-1557. [CrossRef]

20. Aroca-Jiménez, E.; Bodoque, J.M.; García, J.A.; Díez-Herrero, A. A quantitative methodology for the assessment of the regional economic vulnerability to flash floods and implications for risk management. J. Hydrol. 2018, 565, 386-399. [CrossRef]

21. Lastra, J.; Fernández, E.; Díez-Herrero, A.; Marquínez, J. Flood hazard delineation combining geomorphological and hydrological methods: An example in the Northern Iberian Peninsula. Nat. Hazards 2008, 45, 277-293. [CrossRef]

22. MARM. Guía Metodológica para el Desarrollo del Sistema Nacional de Cartografía de Zonas Inundables; Ministerio de Medio Ambiente, y Medio Rural y Marino: Madrid, Spain, 2011; 349p.

23. Ortiz, P.; Antunez, V.; Martín, J.M.; Ortiz, R.; Vázquez, M.A.; Galán, E. Approach to environmental risk analysis for the main monuments in a historical city. J. Cult. Herit. 2014, 15, 432-440. [CrossRef]

24. USACE. Flood Proofing Performance: Successes and Failures; USACE (United States Army Corps of Engineers) National Flood Proofing Committee: Washington, DC, USA, 1998; 120p.

25. Creutin, J.D.; Borga, M.; Gruntfest, E.; Lutoff, C.; Zoccatelli, D.; Ruin, I. A space and time framework for analyzing human anticipation of flash floods. J. Hydrol. 2013, 482, 14-24. [CrossRef]

26. Borga, M.; Stoffel, M.; Marchi, L.; Marra, F.; Jakob, M. Hydrogeomorphic response to extreme rainfall in headwater systems: Flash floods and debris flows. J. Hydrol. 2014, 518, 194-205. [CrossRef]

27. Kelman, I.; Spence, R. An overview of flood actions on buildings. Eng. Geol. 2004, 73, 297-309. [CrossRef]

28. Kreibich, H.; Piroth, K.; Seifert, I.; Maiwald, H.; Kunert, U.; Schwarz, J.; Merz, B.; Thieken, A.H. Is flow velocity a significant parameter in flood damage modelling? Nat. Hazards Earth Syst. Sci. 2009, 9, 1679-1692. [CrossRef]

29. Lonetti, P.; Maletta, R. Dynamic impact analysis of masonry buildings subjected to flood actions. Eng. Struct. 2018, 167, 445-458. [CrossRef]

30. Bellos, B.; Tsakiris, G. Comparing Various Methods of Building Representation for 2D Flood Modelling In Built-Up Areas. Water Resour. Management 2015, 29, 379-397. [CrossRef]

31. Bermúdez, M.; Zischg, A.P. Sensitivity of flood loss estimates to building representation and flow depth attribution methods in micro-scale flood modelling. Nat. Hazards 2018, 92, 1633-1648. [CrossRef] 
32. Vaze, J.; Teng, J.; Spencer, G. Impact of DEM accuracy and resolution on topographic indices. Environ. Modell. Softw. 2010, 25, 1086-1098. [CrossRef]

33. Bodoque, J.M.; Guardiola-Albert, C.; Aroca-Jimenez, E.; Eguibar, M.A.; Martinez-Chenoll, M.L. Flood damage analysis: First floor elevation uncertainty resulting from LiDAR derived digital surface models. Remote Sens. 2016, 8, 604. [CrossRef]

34. Molinari, D.; Scorzini, A.R. On the Influence of Input Data Quality to Flood Damage Estimation: The Performance of the INSYDE Model. Water 2017, 9, 688. [CrossRef]

35. Shen, D.; Qian, T.; Chen, W.; Chi, Y.; Wang, J. A Quantitative Flood-Related Building Damage Evaluation Method Using Airborne LiDAR Data and 2-D Hydraulic Model. Water 2019, 11, 987. [CrossRef]

36. Arrighi, C.; Campo, L. Effects of digital terrain model uncertainties on high-resolution urban flood damage assessment. J. Flood Risk Manag. 2019, e12530. [CrossRef]

37. Mazzorana, B.; Simoni, S.; Scherer, C.; Gems, B.; Fuchs, S.; Keiler, M. A physical approach on flood risk vulnerability of buildings. Hydrol. Earth Syst. Sci. 2014, 18, 3817-3836. [CrossRef]

38. Custer, R.; Nishijima, K. Flood vulnerability assessment of residential buildings by explicit damage process modelling. Nat. Hazards 2015, 78, 461-496. [CrossRef]

39. Figueiredo, R.; Romão, X.; Paupério, E. Flood risk assessment of cultural heritage at large spatial scales: Framework and application to mainland Portugal. J. Cult. Herit. 2019, in press. [CrossRef]

40. Romão, X.; Paupério, E.; Pereira, N. A framework for the simplified risk analysis of cultural heritage assets. J. Cult. Herit. 2016, 20, 696-708. [CrossRef]

41. De Moel, H.; Jongman, B.; Kreibich, H.; Merz, B.; Penning-Rowsell, E.; Ward, P.J. Flood risk assessments at different spatial scales. Mitig. Adapt. Strateg. Glob. Chang. 2015, 20, 865-890. [CrossRef] [PubMed]

42. Garrote, J.; Gutiérrez-Pérez, I.; Díez-Herrero, A. Can the quality of the potential flood risk maps be evaluated? A case study of the social risks of floods in Central Spain. Water 2019, 11, 1284. [CrossRef]

43. Génova, M.; Ballesteros-Cánovas, J.A.; Díez-Herrero, A.; Martínez-Callejo, B. Historical Floods and Dendrochronological Dating of a Wooden Deck in the Old Mint of Segovia, Spain. Geoarchaeology 2011, 26, 786-808. [CrossRef]

44. Génova, M.; Díez-Herrero, A.; Rodríguez-Pascua, M.A.; Moreno-Asenjo, M.A. Natural disasters written in historical woods: Floods, a thunderbolt fire and an earthquake. J. Cult. Herit. 2018, 32, 98-107. [CrossRef]

45. Boletín Oficial del Estado (BOE). Available online: http://www.boe.es/datos/pdfs/BOE/1955/188/A0408804089.pdf (accessed on 13 May 2019).

(C) 2020 by the authors. Licensee MDPI, Basel, Switzerland. This article is an open access article distributed under the terms and conditions of the Creative Commons Attribution (CC BY) license (http://creativecommons.org/licenses/by/4.0/). 